This is a peer-reviewed, accepted author manuscript of the following article: Inglezakis, V. J., Poulopoulos, S. G., \& Kazemian, H. (2018). Insights into the S-shaped sorption isotherms and their dimensionless forms. Microporous and Mesoporous Materials, 272, 166-176. https://doi.org/10.1016/i.micromeso.2018.06.026

\title{
Insights into the S-shaped sorption isotherms and their dimensionless forms
}

\author{
Vassilis J. Inglezakis ${ }^{\mathrm{a}}$, Stavros G. Poulopoulos ${ }^{\mathrm{a}}$ and Hossein Kazemian ${ }^{\mathrm{b}}$ \\ ${ }^{a}$ Environmental Science \& Technology Group (ESTg), Chemical Engineering Department, School of \\ Engineering, Nazarbayev University, 53 Kabanbay batyr ave., Astana, Kazakhstan, e-mail: \\ vasileios.inglezakis@nu.edu.kz;stavros.poulopoulos@nu.edu.kz \\ ${ }^{b}$ College of Science and Management, University of Northern British Columbia (UNBC), Canada, email: \\ Hossein.kazemian@unbc.ca
}

\begin{abstract}
Isotherms are of paramount importance for the interpretation of adsorption and ion exchange mechanisms, and the design of separation and catalytic processes. Although the literature on sorption isotherms is rich, most of experiments and models employed are limited to systems that obey simple equilibrium isotherms, such as linear, favorable or unfavorable types. This paper deals with the rather overlooked S-shaped isotherms and their dimensionless forms, which is of great importance for modeling of separation processes and interpretation of equilibrium data. A review on the physical significance and applications of S-shaped isotherms in adsorption and ion exchange process is also presented.
\end{abstract}

Keywords: S-shaped isotherms, sigmoidal isotherms, adsorption, ion exchange, equilibrium 


\section{Introduction}

Adsorption is a surface phenomenon by which components from a fluid mixture are attracted to the surface of a solid and form physical or chemical bonds with its surface. Ion exchange is the stoichiometric exchange of ions between a liquid and a solid phase, and the nature of attraction is either electrostatic or chemical. Both phenomena are grouped under the term sorption and are frequently treated by unified approaches, at least when it comes to process modeling. Also, both are employed in separation and catalytic processes used in a variety of industrial applications, and are of particular importance in environmental engineering because they are relatively inexpensive and simple to design and operate [1]. The modeling of sorption processes is a challenging task. One of the reasons is the form of the equilibrium isotherms fed into the models. In general, sorption processes modeling requires the simultaneous solution of a set of coupled partial differential equations (PDEs) representing material, energy, and momentum balances supplemented by mass transfer rate equations, equilibrium isotherms and the appropriate initial and boundary conditions. The isotherm shape has a dramatic effect on the sorption process performance, as for instance in fixed bed operations [2]. Besides modeling, isotherms are of primary importance when it comes to the interpretation of the adsorption mechanism and they are used to understand the nature of adsorption [3].

Isotherms are classified according to their curvature: convex-upward (favorable) isotherms and concave-upward (unfavorable) isotherms. In the past, due to the existence of analytical solutions to adsorption process models, mostly rectangular, linear and favorable isotherms were studied [4-6]. However, many systems exhibit more complicated isotherm shapes such as S-shaped (sigmoidal), which have one or more inflections points [7, 8]. For instance, the 
effects of the S-shaped isotherms on adsorption performance of fixed beds has been previously studied $[2,7]$.

A detailed analysis of the adsorption isotherms has been presented in several studies and review papers covering several types of isotherms but only few S-shaped and only in dimensional forms [1, 9]. Recently, Ayawei et al. [10] presented a number of isotherms in dimensional forms, including some sigmoidal which were grouped according to the number of parameters involved. Finally, a number of S-shaped isotherms in dimensional forms are discussed by Furmaniak et al. [11] but the approach is limited to the water-carbon adsorption systems.

In the present paper, S-shaped isotherms with a single inflection point are reviewed in a systematic way. The models addressed are theoretical, empirical and semi-empirical and cover the mechanisms of monolayer and multilayer adsorption and pore filling, excluding capillary condensation phenomena. This study comes to complement the previously published literature on the equilibrium isotherms, covering insights on the physical basis, applications, and a discussion on the dimensionless forms of the S-shaped isotherms, especially useful for separation processes modeling. To the best of the authors' knowledge there is a lack of such a review paper in the literature.

\section{Types of isotherms and classifications}

According to Brunauer's classification there are six types of isotherms [12, 13]: Type-I isotherm is convex upward, Type-III is concave upward, Type-II and Type-V are S-shaped with one inflection point, Type-IV has two inflection points and a hysteresis loop, and TypeVI has several inflection points (Figure 1). An inflection point is a point on a curve at which 
the sign of the curvature (i.e., the concavity) changes, which means that the second derivative of the equilibrium equation is zero. If normalized and presented in a dimensionless fractions $\mathrm{X}-\mathrm{Y}$ diagram, an isotherm with an inflection point crosses the diagonal once $(\mathrm{X}=\mathrm{Y})$.

Figure 1. The Brunauer's classification of isotherms [12]

Giles et al. [3] classified sorption isotherms based on their initial slopes and curvatures, including several types of S-shaped isotherms. This classification is suitable for the general description of sorption isotherms and describes data rather than equations [14]. Hinz [14] presented a set of mathematical criteria for classifying isotherms, which include curvature (convex or concave), slope at low concentration, asymptotic behavior at high fluid or solid phase concentration, and the number of plateaus and inflection points. Finally, Coltharp [15] developed a quantitative means of classifying isotherms according to sign and extent of deviation from the ideal adsorption system (IAS).

According to Sing et al. [13], the Type-II isotherm is obtained with non-porous or macroporous materials. This S-shaped isotherm represents unrestricted monolayer-multilayer adsorption. The middle section of the isotherm, which is almost linear, is often regarded as the stage at which monolayer coverage is complete and multilayer adsorption begins. The Type-IV isotherm is common in mesoporous materials and the characteristic hysteresis loop is associated with capillary condensation taking place in mesopores. The initial part is attributed to monolayer-multilayer adsorption since it follows the same path as the corresponding part of a Type-II isotherm. The Type-V isotherm is obtained only by certain porous adsorbents and it is related to unfavorable equilibrium (Type-III) in that the adsorbent-adsorbate interaction is weak. According to Giles et al. [3], Type-V isotherms are related to microporous materials. Finally, the Type-VI isotherm, represents stepwise multilayer adsorption on a uniform non-porous surface [13]. 
According to Giles et al. [3] and Hinz [14], S-Shaped isotherms may have two causes; firstly, solute-solute attractive forces at the surface may cause cooperative adsorption (positive cooperativity) and secondly, the sorption of a solute may be inhibited by a competing reaction within the solution, such as a complexation reaction with a ligand. This is in agreement with Limousin [9], who states that S-shaped isotherms are always the result of at least two opposite mechanisms. An example of cooperative adsorption is the case of nonpolar organic compounds and surfactants adsorbed on clays. Non-polar organic compounds have low affinity with clays but as soon as a clay surface is covered by these compounds, other organic molecules are adsorbed more easily [9]. Another example is the presence of ligands and their interaction with metals; at low metal concentrations, the adsorption is limited by the presence of the ligand but at higher concentrations adsorption occurs [9]. The point of inflection is the equilibrium concentration where the adsorption overcomes the negative effects of ligand complexation. S-shaped isotherms are not uncommon in ion exchange systems where the selectivity is reversed after the occupation of active sites reaches a certain point. This can be caused by the existence of two types of sites [9]. Adsorption models such as Langmuir and Freundlich are frequently used to describe ion exchange equilibrium although the phenomenon and undelaying mechanisms are different. Ion exchange equilibrium has been presented in detail by Helfferich [16] and Slater [17] and for a rigorous analysis mass-action equilibrium equations are used.

\section{S-shaped isotherms and their dimensionless forms}

Generally, non-dimensionalization (or normalization) of a mathematical model is the removal of the units from an equation by suitable substitution of variables. It is the formulation of the model with dimensionless quantities only, reducing the number of model parameters. While a 
dimensional model provides a solution to a particular problem, the dimensionless approach generalizes the problem and can describe many dimensional solutions. The use of dimensionless numbers helps in normalizing an equation and makes it independent of variables sizes, as for example the reactor dimensions, adsorbent particle size and flow rate used in different experimental setups. These dimensionless numbers provide crucial information on how specific conditions influence systems. Furthermore, the use of a limited set of dimensionless parameters simplifies the numerical solution of the models involved. Thus, in order to use isotherms in process modeling they must first be transformed into their dimensionless forms. Besides process modeling, normalization of the equilibrium curves is useful for the interpretation of the sorption mechanism and is commonly used in ion exchange systems $[18,19]$.

The dimensionless solid phase concentration is $\mathrm{Y}=\mathrm{q} / \mathrm{q}_{\mathrm{o}}$ and that of fluid $\mathrm{X}=\mathrm{C} / \mathrm{C}_{\mathrm{o}}$, where $),(\mathrm{C})$ the fluid phase equilibrium concentration, $\left(\mathrm{C}_{0}\right)$ the initial fluid phase concentration. $(q)$ the solid phase equilibrium concentration, $\left(\mathrm{q}_{\mathrm{o}}\right)$ the (maximum) solid phase equilibrium concentration corresponding to a fluid phase equilibrium concentration of $\left(\mathrm{C}_{\mathrm{o}}\right)$. Then, a dimensionless equilibrium equation must satisfy the conditions $\mathrm{Y} \rightarrow 0$ for $\mathrm{X} \rightarrow 0$ and $\mathrm{Y} \rightarrow 1$ for $\mathrm{X} \rightarrow 1$ and, in particular for $\mathrm{S}$-shaped isotherms, to provide an inflection point $(\mathrm{X}=\mathrm{Y})$ in the whole range of $(\mathrm{X})$.

\subsection{Simple isotherms}

\subsubsection{Dubinin-Astakhov isotherm}

The Dubinin-Astakhov (DA) equation is based on the assumption that the adsorption process follows a pore filling mechanism and accounts for the heterogeneity of the surface. Pore filling mechanism is applicable for microporous materials only [20]. DA equation gives Type- $\mathrm{V}$ isotherms: 


$$
\frac{q}{Q_{M}}=\exp \left[-\left(\frac{1}{\varepsilon_{k}} \cdot \ln \frac{P_{s}}{P}\right)^{n}\right]
$$

where $(\mathrm{P})$ is the gas equilibrium pressure, $\left(\mathrm{P}_{\mathrm{s}}\right)$ is the gas phase saturation pressure (vapor pressure) and $\left(\mathrm{Q}_{\mathrm{M}}\right)$ is the saturation solid phase concentration approached at $\mathrm{P}=\mathrm{P}_{\mathrm{s}}$. For given values of $(\mathrm{n}),\left(\varepsilon_{\mathrm{k}}\right)$ and $\left(\mathrm{P}_{\mathrm{s}}\right)$, the value of $\left(\mathrm{Q}_{\mathrm{M}}\right)$ can be derived as DA allows $(\mathrm{P})$ to reach $\left(\mathrm{P}_{\mathrm{s}}\right)$. For ion exchange systems (or liquid phase adsorption), $\left(\mathrm{P}_{\mathrm{s}}\right)$ is replaced by the saturation concentration of the ion [20]. Furthermore, in ion exchange, (Qм) represents the maximum exchange level (MEL) that can be reached for the specific normality or initial concentration of the incoming ion when the initial solution is free from the ion initially in the solid phase $[20,21]$. Thus, for an ion exchange system with an initial liquid phase concentration of $\left(\mathrm{C}_{\mathrm{o}}\right)$ we have $\mathrm{q}_{\mathrm{o}}=\mathrm{Q}_{\mathrm{M}}$. By applying the above equation for an initial gas pressure $\left(\mathrm{P}_{\mathrm{o}}\right)$ and the respective equilibrium solid concentration $\left(\mathrm{q}_{\mathrm{o}}\right)$ and dividing the two equations, $\left(\mathrm{Q}_{\mathrm{M}}\right)$ is eliminated:

$$
Y=\exp \left[-\left(\frac{1}{\varepsilon_{k}} \cdot \ln \frac{X_{S}}{X}\right)^{n}+\left(\frac{1}{\varepsilon_{k}} \cdot \ln X_{S}\right)^{n}\right]
$$

where $Y=q / q_{o}, X=P / P_{o}$ and $X_{S}=P_{S} / P_{o}\left(X_{S} \geq 1\right), \varepsilon_{k}>0$ and $n>1$ (Figure 2). The same equation is given by Joly and Perrard [22] while Meghea et al. [23] present a different dimensionless form. For $\mathrm{n}=2$ the Dubinin-Radushkevich isotherm is derived.

Figure 2. Dubinin-Astakhov equilibrium equation $\left(\varepsilon_{\mathrm{k}}=2, \mathrm{X}_{\mathrm{S}}=2\right)$

DA isotherm describes well equilibria of many vapors and gases onto microporous activated carbon, carbon molecular sieves, clays and zeolites. An important application is the characterization of microporous materials by $\mathrm{N}_{2}$ and $\mathrm{CO}_{2}$ adsorption $[24,25]$. Also, it has been used for studying liquid phase adsorption; for example the adsorption of phenol on activated carbons, benzene and cyclohexane on coal chars, and many other organics such as 
paracetamol, acetanilide and aniline [26-28]. In ion exchange, a solubility-normalized DA adsorption isotherm has been successfully applied for the removal of lead ions from aqueous solutions by use of natural minerals by Inglezakis et al. [20, 29].

Type-V (DA-like) isotherms are frequently obtained for metal organic frameworks (MOFs), which have inherent structural flexibility due to their weaker bonds compared to relatively rigid frameworks, such as zeolitic aluminosilicates with strong $\mathrm{Si}-\mathrm{O}$ covalent bonds [30]. Zhang et al. [31] evaluated zeolitic imidazolate frameworks (ZIF) for the separation of ethanol/water in vapor phase. As it is illustrated in Figure 3 (a), ethanol showed two distinct steps of adsorption on ZIF with an early stage plateau that happened at low relative pressures. This leads to an S-shaped isotherm of Type-V with low ethanol uptakes at $\mathrm{P} / \mathrm{P}_{\mathrm{o}}$ up to 0.08 and saturation at $\mathrm{P} / \mathrm{P}_{\mathrm{o}}$ higher than 0.08 . This plateau is a significant obstacle toward adsorption of ethanol on ZIF at lower relative pressure and adversely affects the intrinsic capability of ZIF for ethanol/water separation, particularly for dilute solutions of ethanol in water. On the other hand, water adsorption follows the typical Type-II, BET isotherm (see Brunauer-EmmettTeller, section 3.1.2).

Figure 3. (a) Water and ethanol adsorption isotherms in $\mathrm{ZIF}$ at $35^{\circ} \mathrm{C}$. The dashed line is the ideal Langmuir model fit for ethanol in the hypothetical absence of initial sorption plateau (b) Detailed water adsorption isotherm in ZIF crystals at $35^{\circ} \mathrm{C}$. "Reprinted with permission from \{ Zhang, K., Lively, R. P., Zhang, C., Koros, W. J., Chance, R. R., (2013), J. Phys. Chem. C, 117, 7214-7225\}. Copyright $\{2018\}$ American Chemical Society."

Another Type-V isotherm is that of Meghea et al. [23] derived using the Boltzmann equation. The advantage of this isotherm consists in its well-fitting of some experiments including special cases, such as the charge transfer complexes formed in some bi-solute competitive adsorption. The equation is: 


$$
Y=\frac{\left(A_{1}-A_{2}\right)}{1+\exp \left(\frac{X-B_{0}}{B_{1}}\right)}+A_{2}
$$

Where $\mathrm{A}_{1}, \mathrm{~A}_{2}, \mathrm{~B}_{0}$ and $\mathrm{B}_{1}$ constants (Figure 4). Meghea model has been used to describe the adsorption of phenolic compounds from water on activated carbon [23].

Figure 4. Meghea equilibrium equation $\left(\mathrm{A}_{2}=1, \mathrm{~B}_{0}=0.425, \mathrm{~B}_{1}=0.0615\right)$.

In the case of water adsorption on carbons, the mechanism can be different than micropore filling, i.e. cluster formation mechanism. For such systems, there is a number of DA-like Type-V isotherms, as the Dubinin-Serpinski, Mahle and Talu, and Meunier isotherms presented by Furmaniak et al. [11], which are not repeated here as they are very close to the shape given by the DA isotherm.

\subsubsection{Brunauer-Emmett-Teller isotherm}

Brunauer-Emmett-Teller (BET) equation accounts for multilayer adsorption with no limit in the number of layers, which can be accommodated on the energetically homogeneous surface. According to the BET model, the adsorbed molecules in one layer can act as adsorption sites for molecules in the next layer [32]. BET gives Type-II isotherms:

$$
\frac{q}{q_{M}}=\frac{k \cdot\left(P / P_{S}\right)}{\left(1-P / P_{S}\right) \cdot\left(1-P / P_{S}+k \cdot P / P_{S}\right)}
$$

where $(P)$ and $(q)$ are the gas phase pressure and solid phase equilibrium concentration, respectively, $\left(\mathrm{P}_{\mathrm{s}}\right)$ is the gas phase saturation pressure, $\left(\mathrm{q}_{\mathrm{M}}\right)$ is the monolayer coverage concentration of the solid phase and $\mathrm{k}>0$. In contrast to the DA equation, BET does not have a finite solid phase concentration limit (saturation), and as the fluid phase concentration reaches the saturation concentration, the solid phase concentration limit is infinite. Thus, while DA allows the determination of $\left(\mathrm{Q}_{\mathrm{M}}\right)$ by letting $\mathrm{P}=\mathrm{P}_{\mathrm{s}}$, this is not possible in the case of 
BET, and ( $\left.\mathrm{q}_{\mathrm{M}}\right)$ is calculated in a different way. By applying the above equation for an initial gas pressure $\left(\mathrm{P}_{\mathrm{o}}\right)$ and the respective equilibrium solid concentration $\left(\mathrm{q}_{\mathrm{o}}\right)$, and then dividing the two equations, $\left(\mathrm{q}_{\mathrm{M}}\right)$ is eliminated:

$$
Y=\frac{X \cdot\left(X_{S}-1\right) \cdot\left(X_{S}-1+k\right)}{\left(X_{S}-X\right) \cdot\left(X_{S}-X+k \cdot X\right)}
$$

where $X_{S}=P_{S} / P_{o}\left(X_{S}>1\right)$ and $k>0$. The BET dimensional form gives S-shaped isotherms for certain combinations of $\left(\mathrm{X}_{\mathrm{S}}\right)$ and $(\mathrm{k})$ (Figure 5). A different dimensionless BET form is provided by Meghea et al. [23].

BET equation remains the most widely used of all adsorption isotherm equations and it is extensively used for determining the surface area of porous and non-porous adsorbents [32]. BET isotherm is popular in water vapor adsorption applications (see Figure 3a) and gas-phase adsorption [11, 33]. Furthermore, the BET equation has been used for the adsorption of phenolic compounds from water by use of activated carbon [23].

Concerning water vapor adsorption, the shape of the isotherm depends on the specific type of carbon and can be either Type-II or Type-V. Furmaniak et al. [11] presents a set of BET-like Type-II isotherms for the adsorption of water on carbons like D'Arcy and Watt isotherm, and Guggenheim, Anderson and de Boer model which are not repeated here as they are very close to the shape given by the BET isotherm. Finally, modified BET isotherms have been applied to several systems, as for example by Woodruff and Revil [34] for the sorption and desorption of bound water in clays, sand-clay mixtures, and shales, and by Tan and O'Haver [35] for the adsorption of styrene from liquid solutions onto silica.

Figure 5. Brunauer-Emmett-Teller equilibrium equation 
Stokes and Robinson [36] adapted the BET model for concentrated aqueous electrolyte solutions assuming that salts in solution have several sites of adsorption for solvent. They proposed a relation between the water activity and stoichiometric mole fraction of the salt, and introduced a constant related to the heat of adsorption of water (monomolecular layer solvation). Letellier et al. [37] employed this modified BET model to study the mixing behavior of different surfactants beyond their aggregation threshold. This model describes the properties of mixed micelles of two pure surfactants in a wide composition range. The BET model has also been used to the water-nitric acid system for the determination of mean ionic activity coefficients [38].

\subsubsection{Equation of State-derived isotherms}

Based on the corresponding-states equation (CSE), Radke and Prausnitz [39] derived a semitheoretical correlation for the adsorption from dilute solutions. The equation is also called Virial Isotherm [23, 39]:

$$
\frac{K_{o} \cdot X}{Y}=1+K_{1} \cdot Y+K_{2} \cdot Y^{2}+\cdots
$$

where the constants $\left(\mathrm{K}_{\mathrm{i}}\right)$ are called adsorption virial coefficients. This equation gives Type-V isotherms for $\mathrm{K}_{0}>0, \mathrm{~K}_{1}<0$ and $\mathrm{K}_{2}>0$ (Figure 6). The CSE model was used for the adsorption of phenolic compounds from water by use of activated carbon [23].

Figure 6. CSE equilibrium equation

An equation of the same form but with four terms is given by Vermeulen [40]. Vermeulen et al. [41] provided one more equation, this time with three terms (trinomial), solved for both $\mathrm{X}$ (as above) and (Y) but without any discussion on their derivation. The equation is: 


$$
Y=\left(1-k_{1}-k_{2}\right) \cdot X+k_{1} \cdot X^{2}+k_{2} \cdot X^{3}
$$

This equation gives Type- $\mathrm{V}$ isotherms for $\mathrm{k}_{1}>0$ and $3 \cdot \mathrm{k}_{2}<-\mathrm{k}_{1}$ and, less successfully, Type-II isotherms for $\mathrm{k}_{1}<0$ and $3 \cdot \mathrm{k}_{2}>-\mathrm{k}_{1}$ (Figure 7). Ruthven [6] presented this equation with an additional term, derived from statistical thermodynamic models. Trinomial equations have been used in ion exchange systems [42].

Figure 7. Trinomial equilibrium equation

\subsubsection{Ion exchange equilibria}

Concerning ion exchange equilibria, S-shaped isotherms are frequently encountered and are successfully modeled by use of rigorous albeit complex ion exchange equilibrium models, an analysis which is beyond the scope of the present paper $[18,19]$. The mass-action equation in its simplified form for binary systems is [54]:

$$
K_{A B}=\left(\frac{\overline{E_{A}}}{E_{A}}\right)^{z_{B}} \cdot\left(\frac{E_{B}}{\overline{E_{A}}}\right)^{z_{A}} \cdot\left(\frac{N}{Q_{M}}\right)^{z_{A}-z_{B}}
$$

where $\left(\mathrm{K}_{\mathrm{AB}}\right)$ is the equilibrium constant, $(\bar{E})$ and $(\mathrm{E})$ the equivalent fractions in solid and liquid phase of ions $\mathrm{A}$ and $\mathrm{B},(\mathrm{N})$ is the solution normality (constant in ion exchange) and (QM) the ion exchanger capacity in equivalents. Molar and equivalent concentrations are related by $\mathrm{N}_{\mathrm{i}}=\mathrm{Z}_{\mathrm{i}} \cdot \mathrm{C}_{\mathrm{i}}$, where $\left(\mathrm{Z}_{\mathrm{i}}\right)$ is the ion valence. This simplified version of equilibrium constant is valid for ideal solution behavior otherwise activities must be used, rendering the equation and determination of several parameters a tedious and complex task. The equilibrium constants can be calculated by use of thermodynamics or determined by use of experimental techniques and then used with mass-action equation to provide a relationship between liquid and solid compositions. Solving for the solid phase concentration, a relationship between the liquid and solid phase equivalent fractions can be derived, giving equations in the form of adsorption $\mathrm{X}-\mathrm{Y}$ isotherms: 


$$
\bar{E}=f\left(K_{A B}, E_{i}, n\right)
$$

For example, for the exchange of monovalent ions in ideal solutions the equilibrium constant becomes a simple expression of molar fractions:

$$
K_{A B}=\frac{Y_{A} \cdot X_{B}}{X_{A} \cdot Y_{B}}=\frac{Y_{A} \cdot\left(1-X_{A}\right)}{X_{A} \cdot\left(1-Y_{A}\right)}=\frac{X_{B} \cdot\left(1-Y_{B}\right)}{Y_{B} \cdot\left(1-X_{B}\right)}
$$

Solving for the solid phase equilibrium concentration of ion (B), this equation takes the following familiar form of the dimensionless Langmuir isotherm:

$$
Y=\frac{X}{K+(1-K) \cdot X}
$$

Solving for the solid phase equilibrium concentration of ion (A) we get:

$$
Y=\frac{K \cdot X}{1+(K-1) \cdot X}
$$

For $\mathrm{K}<1$ the first isotherm is favorable and the second unfavorable and the opposite for $\mathrm{K}>1$.

\subsection{Hybrid isotherms}

Hybrid isotherms are modifications or combinations of simple models able to represent more complex systems. Isotherms based on the multisite (heterogeneous) solid phase concept are presented in paragraph 3.3.

\subsubsection{Modified Langmuir isotherms}

Gu et al. [43] developed a semi-theoretical model based on Langmuir isotherm, named Modified Langmuir model or Modified Langmuir Model with q-Dependent Affinity (QKLM) [44]. The model equation is:

$$
\frac{q}{Q_{M}}=\frac{k(q) \cdot C}{1+k(q) \cdot C}
$$

where $\mathrm{k}(\mathrm{q})$ is defined as surface excess-dependent affinity parameter:

$$
k(q)=k \cdot e^{-2 b q}
$$


The parameter (b) presumably takes into account the features of changing energies of adsorption with changing surface coverage. This model was successfully applied for the adsorption of natural organic matter on iron oxide [43]. Due to the dependence of the affinity parameter on the solid phase loading, the above equation cannot be normalized; however an equivalent non-dimensional form can be the following:

$$
Y=\frac{X}{K \cdot e^{-B Y}+\left(1-K \cdot e^{-B Y}\right) \cdot X}
$$

The QKLM model gives both Type-II and Type-V isotherms (Figure 8). The dimensionless form, as well as the original equation devised by Gu et al. [43] becomes the Langmuir model for $\mathrm{B}=0$ or $\mathrm{b}=0$, respectively.

Figure 8. QKLM model

Zhu and $\mathrm{Gu}$ [45] model is not a combination of isotherms but a combination of two-step adsorption and mass action models. The isotherm is:

$$
\frac{q}{Q_{M}}=\frac{k_{1} \cdot C \cdot\left(\frac{1}{n}+k_{2} \cdot C^{n-1}\right)}{1+k_{1} \cdot C \cdot\left(1+k_{2} \cdot C^{n-1}\right)}
$$

For certain combinations of $\left(\mathrm{k}_{1}\right),\left(\mathrm{k}_{2}\right)$ and $(\mathrm{n})$ this equation gives Langmuir (Type-I), Sshaped (Type-V) and isotherms with two plateaus (Type-IV). When $\mathrm{k}_{2} \cdot \mathrm{C}^{\mathrm{n}-1}>>1$ the equation is reduced to Sips isotherm with $\mathrm{K}=\mathrm{k}_{1} \cdot \mathrm{k}_{2}$ (see section 3.2.1). Zhu and $\mathrm{Gu}$ [45] applied this equation in the adsorption of surfactants on carbons and silica gel. The two-step adsorption mechanism was proposed where the surfactant molecules are firstly adsorbed through the interactions between the molecules and the solid surface through electrostatic and/or specific (e.g. van der Waals) attraction, and then through the hydrophobic interaction between the adsorbed surfactant molecules, a step in which the adsorption increases dramatically. Also, Zhu and Gu model was used by Markou et al. [46] for the sorption of orthophosphate on 
modified bentonite. The model successfully interpreted the experimental data and suggested antagonistic interactions on the surface of the solid phase.

In $\mathrm{Zhu}$ and $\mathrm{Gu}$ equation, $\left(\mathrm{Q}_{\mathrm{M}}\right)$ cannot be eliminated and the dimensionless form is essentially the same as the dimensional one:

$$
Y=\frac{\left(Y_{M} \cdot K_{1}\right) \cdot X \cdot\left(\frac{1}{n}+K_{2} \cdot X^{n-1}\right)}{1+K_{1} \cdot X \cdot\left(1+K_{2} \cdot X^{n-1}\right)}
$$

where $\mathrm{K}_{1}=\mathrm{k}_{1} \mathrm{C}_{\mathrm{o}}$ and $\mathrm{K}_{2}=\mathrm{k}_{2} \mathrm{C}_{\mathrm{o}}{ }^{\mathrm{n}-1}$. Also, the requirement $\mathrm{Y} \rightarrow 1$ for $\mathrm{X} \rightarrow 1$ gives the following condition:

$$
Y_{M}=\left[\frac{K_{1} \cdot\left(\frac{1}{n}+K_{2}\right)}{1+K_{1}\left(1+K_{2}\right)}\right]^{-1}
$$

This equation gives an inflection point for $\mathrm{K}_{1}>0, \mathrm{~K}_{2}>0$ and $\mathrm{n}>1$ (Figure 9).

Figure 9. Zhu and Gu equilibrium equation.

A purely empirical equation is given by Limousin et al. [9] and is called sigmoidal Langmuir:

$$
\frac{q}{Q_{M}}=\frac{k_{1} \cdot C}{1+k_{1} \cdot C+\frac{k_{2}}{C}}
$$

where $\left(\mathrm{Q}_{\mathrm{M}}\right)$ is the maximum solid capacity. In this equation, $\left(\mathrm{Q}_{\mathrm{M}}\right)$ cannot be eliminated and the dimensionless form is essentially the same as the dimensional one:

$$
Y=\frac{Y_{M} \cdot X}{K_{1}+X+\frac{K_{2}}{X}}
$$

where $\mathrm{Y}_{\mathrm{M}}=\mathrm{Q}_{\mathrm{M}} / \mathrm{q}_{\mathrm{o}}\left(\mathrm{Y}_{\mathrm{M}} \geq 1\right), \mathrm{K}_{1}=1 / \mathrm{k}_{1} \mathrm{C}_{\mathrm{o}}$ and $\mathrm{K}_{2}=\mathrm{K}_{1} \mathrm{k}_{2} / \mathrm{C}_{\mathrm{o}}\left(\mathrm{K}_{2}>0\right)$. Also, the requirement $\mathrm{Y} \rightarrow 1$ for $\mathrm{X} \rightarrow 1$ gives the following condition: $\mathrm{K}_{1}+\mathrm{K}_{2}=\mathrm{Y}_{\mathrm{M}}-1$. This isotherm is of Type- $\mathrm{V}$ 
isotherms (Figure 10). The problem with this isotherm is that its curvature which is close to the linear isotherm.

Figure 10. Sigmoidal Langmuir equilibrium equation

\subsubsection{Sips isotherm}

Sips isotherm is a combination of Langmuir and Freundlich isotherms [47]:

$$
\frac{q}{Q_{M}}=\frac{k \cdot C^{n}}{1+k \cdot C^{n}}
$$

The parameter (n) could be regarded as characteristic of the heterogeneity of the surface and the larger is this parameter the more heterogeneous is the system.

Sips model assumes monolayer coverage and is useful to describe adsorption of gases and vapors below the capillary condensation region [47]. For instance, Kayal et al. [48] studied water adsorption properties of zeolites for application in adsorption chillers. They found that water vapor adsorption on these materials exhibited a Type-V isotherm with hydrophobic behavior at lower pressures. Dubinin Astakhov (DA) and a modified Sips model were used to correlate the data. Sips model has also been used for adsorption in liquid phase, as for example in triclosan adsorption on diatomite [49], and bio-sorption of heavy metals ions, as for chromium and copper on Sargassum sp [50] and nickel on S. pombe [51]. Moreover, Sips model is proven to be useful in cases where Langmuir and Freundlich isotherms fail, as for example in pH-dependent adsorption. Jeppu and Clement [52] suggested the Sips model, referred to as modified Langmuir-Freundlich (MLF) isotherm, for the $\mathrm{pH}$-dependent adsorption of As (V) onto pure goethite and goethite-coated sand adsorbents.

Grant et al. [44] aimed at developing a series of modified Langmuir equations that could be used on S-shaped experimentally-derived isotherms. They studied the adsorption of two 
mycotoxins, aflatoxin B1 (AfB1) and cyclopiazonic acid (CPA) on two clays, kaolinite and montmorillonite). The several forms of Langmuir isotherm, i.e. simple, multi-site composite (see section 3.3) and the q-dependent affinity (QKLM) isotherm did not fit adequately the experimental data that displayed multisite adsorption or multiple plateaus. Therefore, they suggested several modifications of the Langmuir models based on the insertion of an additional constant, which represented the concentration value on the concentration axis necessary to shift a Langmuir-shaped isotherm to match part of an S- or complex-shaped isotherm. These shifted-modified Langmuir isotherms are essentially Sips isotherms with an additional variable to account for the shift, i.e. the liquid phase concentration (C) is replaced with $\left(\mathrm{C}-\mathrm{C}_{\mathrm{s}}\right)$, where $\left(\mathrm{C}_{\mathrm{s}}\right)$ is the shifted concentration. Figure 11 illustrates the data of AfB1 adsorption on kaolinite fitted by LM, QKLM, and the SQKLM models.

Figure 11. Isotherm data of AfB1 adsorption onto kaolinite fit by the Langmuir model (LM), the q-dependent affinity modification of the Langmuir model (QKLM), and the shifted QKLM (SQKLM). "Reprinted with permission from \{Grant, P. D., Lemke, S. L., Dwyer, M. R., Phillips, T. D. (1998), Langmuir, 14, 4292-4299\}. Copyright \{2018\} American Chemical Society."

Sips isotherm can be normalized in the same way as the Langmuir isotherm, by setting [17]:

$$
K=\frac{1}{1+k \cdot C_{o}^{n}}
$$

Then, by applying the equilibrium equation for an initial liquid concentration $\left(\mathrm{C}_{\mathrm{o}}\right)$ and the respective equilibrium solid concentration $\left(\mathrm{q}_{\mathrm{o}}\right)$, and dividing the two equations, $\left(\mathrm{Q}_{\mathrm{M}}\right)$ is eliminated: 


$$
Y=\frac{X^{n}}{K+(1-K) \cdot X^{n}}
$$

where $\mathrm{K}>0$ and $\mathrm{n}>0$. This isotherm is also called Langmuir-Freundlich isotherm and is considered to be empirical [9, 14, 23, 47]. Furthermore, it gives both Type-II and Type-V isotherms (Figure 12).

Figure 12. Sips equilibrium equation

A similar to Sips model and purely empirical is given by Vermeulen [40] in an article where he presents a variety of isotherms, including an empirical equation for S-shaped isotherms:

$$
Y=\frac{X^{n}}{X^{n}+K \cdot(1-X)^{n}}
$$

where $\mathrm{K}>0$. This equation fits both Type-II $(0<\mathrm{n}<1)$ and Type-V $(\mathrm{n}>1)$ (Figure 13).

Figure 13. Vermeulen equilibrium equation $(K=1.5)$

\subsection{Composite isotherms}

Adsorption equilibrium data of a number of microporous solids do not conform to the simple isotherms, which has been attributed to the heterogeneity of the solids surface [47]. For these cases, composite isotherms or the so-called inhomogeneous models can be used to describe multisite (heterogeneous) solid phases behaving differently towards the same component. One simple approach is to assume that the solid is composed of two distinct regions with no interaction between them. With this assumption equilibrium equations can be applied to each region and the overall isotherm is simply the summation of the two equations $[6,47]$. 


\subsubsection{Double Selectivity Model}

Limousin et al. [9] discuss the use of the modified Langmuir models for multisite or competitive adsorption. For example, in the case of the existence of two types of adsorption sites, which occupy (p) sites on the solid, the isotherm takes the form:

$$
q=\sum_{i=1}^{p} Q_{M, i} \cdot \frac{K_{i} \cdot C}{1+K_{i} \cdot C}
$$

A similar approach has been followed for the DA isotherm deriving the so-called Modified Dubinin Equations [47]. The idea has been extended and successfully applied on ion exchange systems with selectivity reversal. In binary ion exchange systems, this selectivity reversal means that the preferential affinity of the solid for one of the two ions shifts to the other ion when the fraction of active sites occupied by the first ion reaches a certain value, and this can be caused by the existence of two types of sites. Bricio at al. [53] and later Pepe et al. [54] developed the Double Selectivity Model (DSM) for heterogeneous ion exchangers by using the concept of multisite adsorption. The general form is the one of modified Langmuir models:

$$
\bar{E}=p \cdot \overline{E_{1}}+(1-p) \cdot \overline{E_{2}}
$$

where the solid phase equivalent fractions are given by the respective equilibrium constants $\left(\mathrm{K}_{\mathrm{AB}}\right)$ of each type of sites. For example, in the case of the exchange of monovalent ions, the derived equation is:

$$
Y=p \cdot \frac{K_{1} \cdot X}{1+\left(K_{1}-1\right) \cdot X}+(1-p) \cdot \frac{K_{2} \cdot X}{1+\left(K_{2}-1\right) \cdot X}
$$


This approach is particularly useful as it gives Type-II isotherms and can correlate experimental data by fitting $(\mathrm{p}),\left(\mathrm{K}_{1}\right)$ and $\left(\mathrm{K}_{2}\right)$ without the need for the numerous and difficult to be derived equilibrium constants (Figure 14).

Figure 14. Double Selectivity Model equilibrium equation $\left(\mathrm{K}_{1}=8, \mathrm{~K}_{2}=0.2\right)$

DSM models have been used for the ion exchange of cations on resins by Bricio et al. [53] and zeolites by Pepe et al. [54] and Iucolano et al. [55].

\subsubsection{Langmuir-Sips model}

Hsu et al. [56] and Lee et al. [57] discuss the application of a composite Langmuir-Sips isotherm on water and organic compounds, respectively. Lee et al. [57] employs this model as it can represent equilibrium data by Langmuir isotherm at low pressure and Sips isotherm at moderate pressure to account for capillary condensation. Lee et al. [57] present the following form of the Langmuir-Sips equation:

$$
q=m \cdot\left[\frac{k \cdot P}{1+k \cdot P}+\frac{k_{1} \cdot P^{n}}{1+k_{1} \cdot P^{n}}\right]
$$

The Langmuir-Sips equation finds application also in the adsorption of vapors of polar and nonpolar organic compounds on mesoporous silicate and the water adsorption on a silicabased high-purity spherical gel $[56,57]$. The latter is a Type-V isotherm, as shown in Figure 15.

Figure 15. Variations of the adsorbed water at equilibrium (Meq) (at room temperature) for different relative humidity $(\mathrm{RH})$ levels for various adsorbents. The red dashed curve is the theoretical fitting of the M. S. Gel isotherm by the modified Langmuir-Sips theory. "Reprinted with permission from $\{$ Hsu, W.-L., Paul, S., Shamim, J. A., Kitaoka, K., Daiguji, 
H. (2018), International Journal of Heat and Mass Transfer, 116, 1370-1378\}. Copyright $\{2018\}$ Elsevier."

Wu et al. [58] used a zeolitic imidazolate framework (ZIF) for the separation of $\mathrm{CO}_{2}$ from $\mathrm{CH}_{4}$ in a vacuum swing adsorption process. The derived isotherms were of Type- $\mathrm{V}$ and Type-IV. A modified triple-site Sips equation was proposed for representing the experimental data. The solid lines in Figure 16 represent the modified triple-site Sips isotherm model.

Figure 16. Adsorption isotherms of $\mathrm{CO}_{2}$ on ZIF; filled symbols, adsorption; open symbols, desorption; solid line, modified dual-site Sips equation. "Reprinted with permission from \{Wu, X.,Shahrak, M.N., Yuan, B., Deng, S., (2014), Microporous and Mesoporous Materials, 190, 189-196.\}. Copyright $\{2018\}$ Elsevier."

Following the same procedure as in the normalization of Sips equation:

$$
\begin{aligned}
K & =\frac{1}{1+k \cdot P_{o}} \\
K_{1} & =\frac{1}{1+k_{1} \cdot P_{o}^{n}}
\end{aligned}
$$

Then:

$$
Y=0.5 \cdot\left[\frac{X}{K+(1-K) \cdot X}+\frac{X^{n}}{K_{1}+\left(1-K_{1}\right) X^{n}}\right]
$$

The normalized equation gives $\mathrm{Y} \rightarrow 2$ for $\mathrm{X} \rightarrow 1$ and thus the factor 0.5 is introduced in order to fulfill the condition $\mathrm{Y} \rightarrow 1$ for $\mathrm{X} \rightarrow 1$. This equation can give Type II, Type $\mathrm{V}$ as well as isotherms with more than one inflection points (Figure 17). This correction is not needed if two types of adsorption sites are allowed leading to a modified Langmuir-Sips equation:

$$
Y=p \cdot \frac{X}{K+(1-K) \cdot X}+(1-p) \cdot \frac{X^{n}}{K_{1}+\left(1-K_{1}\right) X^{n}}
$$


A multisite heterogeneous model similar to the above one is the Do-Do [11]. The basic difference is that the Do-Do model is comprised of two Sips equations with different exponents able to give Type-IV isotherms with more than one inflection points.

Figure 17. Langmuir-Sips equilibrium equation

\subsubsection{Langmuir-Ising model}

Rutherford [59] presented a composite isotherm with contributions from the Ising equation, representing the first mode of adsorption, and the Langmuir equation, representing the second mode of adsorption. The Langmuir-Ising equation is:

$$
q=\frac{Q_{M} \cdot k \cdot\left(P / P_{S}\right)}{1+k \cdot\left(P / P_{S}\right)}+\frac{Q_{M 1} \cdot k_{1} \cdot\left(P / P_{S}\right)}{k_{1} \cdot\left(P / P_{S}\right)+w^{2}}
$$

where

$$
w=0.5 \cdot\left[1-k_{2} \cdot\left(P / P_{S}\right)+\sqrt{\left(1-k_{2} \cdot\left(P / P_{S}\right)\right)^{2}+4 \cdot k_{1} \cdot\left(P / P_{S}\right)}\right]
$$

In this equation $\left(\mathrm{Q}_{\mathrm{M}}\right)$ cannot be eliminated and the dimensionless form is essentially the same as the dimensional one:

$$
Y=p \cdot \frac{Y_{T} \cdot k \cdot\left(X / X_{S}\right)}{1+k \cdot\left(X / X_{S}\right)}+(1-p) \cdot \frac{Y_{T} \cdot k_{1} \cdot\left(X / X_{S}\right)}{k \cdot\left(X / X_{S}\right)+w^{2}}
$$

Where $\mathrm{X}_{\mathrm{s}}=\mathrm{P}_{\mathrm{S}} / \mathrm{P}_{\mathrm{o}}\left(\mathrm{X}_{\mathrm{s}} \geq 1\right), \mathrm{Y}_{\mathrm{T}}=\mathrm{Q}_{\mathrm{T}} / \mathrm{q}_{\mathrm{o}}\left(\mathrm{Y}_{\mathrm{T}} \geq 1\right), \mathrm{Q}_{\mathrm{T}}=\mathrm{Q}_{\mathrm{M}}+\mathrm{Q}_{\mathrm{M} 1}$ and $\mathrm{p}=\left(\mathrm{Q}_{\mathrm{M}} / \mathrm{Q}_{\mathrm{T}}\right)$. Also: 


$$
w=0.5 \cdot\left[1-k_{2} \cdot\left(X / X_{S}\right)+\sqrt{\left(1-k_{2} \cdot\left(X / X_{S}\right)\right)^{2}+4 \cdot k_{1} \cdot\left(X / X_{S}\right)}\right]
$$

This equation can provide BET-like as well as other Type-II and Type-V isotherms (Figure 18). Although different in form, Malakhov and Volkov model, based on the cooperative multimolecular sorption mechanism, also gives both Type-II and Type-V isotherms and can be reduced to the Ising and/or BET models $[11,61]$.

Figure 18. Langmuir-Ising equilibrium equation $\left(\mathrm{Y}_{\mathrm{T}}=1.5, \mathrm{X}_{\mathrm{S}}=2\right)$

Langmuir-Ising model was used by Rutherford [59] for the adsorption of water vapors on carbon molecular sieves. Another application of the model was the $\mathrm{CO}_{2}$ adsorption from the main flue gas components on carbon honeycomb monoliths with different textural development in a pressure and temperature range of interest for post-combustion $\mathrm{CO}_{2}$ capture [60]. Malakov et al. [61] used a similar model for the adsorption of alcohols on polymeric materials.

The isotherms discussed in this paper are summarized in Table 1. Some of the reported SShape isotherms for different adsorption/separation process in both gas and liquid phases are shown in Table 2.

Table 1. Summary of S-shaped isotherms

\begin{tabular}{|c|c|c|c|}
\hline Isotherm & S-shaped type & $\begin{array}{c}\text { Number of } \\
\text { variables }\end{array}$ & Derivation \\
\hline Brunauer-Emmett- & II & 2 & Theoretical \\
Teller & & & \\
\hline Sips & II, V & 2 & Empirical \\
\hline
\end{tabular}




\begin{tabular}{|c|c|c|c|}
\hline QK Langmuir model & II, V & 2 & Semi-theoretical \\
\hline Trinomial & II, V & 2 & Empirical \\
\hline Vermeulen & II, V & 2 & Empirical \\
\hline Sigmoidal Langmuir & V & 3 & Empirical \\
\hline Dubinin-Astakhov & V & 3 & Semi-empirical \\
\hline Langmuir-Sips & II, V & 3 & Empirical \\
\hline DSM & II & 3 & Theoretical \\
\hline CSE & V & 3 & Semi-theoretical \\
\hline Langmuir-Ising & II, V & 4 & Empirical \\
\hline Zhu-Gu & V & 4 & Theoretical \\
\hline Meghea & V & 4 & Empirical \\
\hline
\end{tabular}

Table 2. Typical S-Shape isotherms reported for different adsorption/separation processes

\begin{tabular}{|c|c|c|c|c|c|}
\hline Solid phase & $\begin{array}{l}\text { Isotherm } \\
\text { type }\end{array}$ & Models(s) & $\begin{array}{l}\text { Fluid } \\
\text { phase }\end{array}$ & Component(s) & Reference \\
\hline \multicolumn{6}{|c|}{ Ion exchange } \\
\hline Natural zeolite & Type-II & $\begin{array}{l}\text { Several arbitrary } \\
\text { polynomial } \\
\text { expressions }\end{array}$ & Liquid & Chromium (III) & Barros et al. [62] \\
\hline Resins & Type-II & $\begin{array}{l}\text { Double selectivity } \\
\text { model (DSM) }\end{array}$ & Liquid & Several cations & Bricio et al. [53] \\
\hline Zeolite & Type-II & $\begin{array}{l}\text { Double selectivity } \\
\text { model (DSM) }\end{array}$ & Liquid & Several cations & Pepe et al. [54] \\
\hline Zeolite & Tyoe-II & $\begin{array}{l}\text { Double selectivity } \\
\text { model (DSM) }\end{array}$ & Liquid & Lead & Iucolano et al. [55] \\
\hline Zeolite & Type-I & Modified DA model & Liquid & Lead & Inglezakis [20] \\
\hline Zeolite and clays & Type-I & Modified DA model & Liquid & Lead & Inglezakis et al. [29] \\
\hline Natural zeolite & Type-II & No model applied & Liquid & Heavy metals & Inglezakis et al. [63] \\
\hline \multicolumn{6}{|c|}{ Adsorption } \\
\hline Coal chars & Type-V & DA model & Liquid & $\begin{array}{l}\text { Benzene and } \\
\text { cyclohexane }\end{array}$ & $\begin{array}{l}\text { Siemieniewska et } \\
\text { al. [26] }\end{array}$ \\
\hline Carbon & Type-V & DA model & Liquid & Several organics & Terzyk [27] \\
\hline Carbons & Type-V & DA model & Gas & $\mathrm{CO}_{2}$ & Burevski [24] \\
\hline Carbons and clays & Type-V & DA model & Gas & $\mathrm{N}_{2}$ & Gil and Grange [25] \\
\hline Aluminophosphate & Type-V & DA model & Gas & $\mathrm{H}_{2} \mathrm{O}$ & Kayal et al. [48] \\
\hline
\end{tabular}




\begin{tabular}{|c|c|c|c|c|c|}
\hline based zeolites & & $\begin{array}{l}\text { Sips model } \\
\text { (Modified Langmuir } \\
\text { equation) }\end{array}$ & & & \\
\hline Silica & Type-II & Modified BET & Liquid & Styrene & $\begin{array}{l}\text { Tan and O'Haver } \\
{[35]}\end{array}$ \\
\hline Activated carbon & Type-V & $\begin{array}{l}\text { BET, DA and CSE } \\
\text { and Meghea et al. } \\
\text { models }\end{array}$ & Liquid & Phenols & Meghea et al. [23] \\
\hline $\begin{array}{l}\text { Goethite and } \\
\text { goethite-coated sand } \\
\text { adsorbents }\end{array}$ & Type-I & Sips isotherm & Liquid & As (V) & $\begin{array}{l}\text { Jeppu and Clement } \\
{[52]}\end{array}$ \\
\hline Diatomite mineral & Type-II & Sips isotherm & Liquid & Triclosan & Sharipova et al. [49] \\
\hline $\begin{array}{l}\text { Kaolinite } \\
\text { Montmorillonite }\end{array}$ & Type-V & $\begin{array}{l}\text { Shifted squared } \\
\text { Langmuir model } \\
\text { (Modified Sips } \\
\text { model with } n=2 \text { ) }\end{array}$ & Liquid & $\begin{array}{l}\text { Aflatoxin B1 (AfB1) } \\
\text { Cyclopiazonic acid } \\
\text { (CPA) }\end{array}$ & Grant et al. [44] \\
\hline $\begin{array}{l}\text { Zeolitic imidazolate } \\
\text { frameworks (ZIFs) }\end{array}$ & \begin{tabular}{|l} 
Type-V \\
Type-IV
\end{tabular} & $\begin{array}{l}\text { Modified triple-site } \\
\text { Sips equation }\end{array}$ & Gas & $\mathrm{CO}_{2} / \mathrm{CH}_{4}$ & Wu et al. [58] \\
\hline Modified bentonite & Type-V & Zhu and Gu model & Liquid & Orthophosphate & Markou et al. [46] \\
\hline Carbon and silica gel & \begin{tabular}{|l|} 
Type-V \\
Type-IV
\end{tabular} & Zhu and Gu model & Liquid & Surfactants & Zhu and $\mathrm{Gu}[45]$ \\
\hline Silica-based materials & Type-V & \begin{tabular}{|l|} 
Langmuir-Sips \\
model
\end{tabular} & Gas & $\mathrm{H}_{2} \mathrm{O}$ & Hsu et al. [56] \\
\hline Mesoporous silicate & \begin{tabular}{|l} 
Type-II \\
Type-IV
\end{tabular} & $\begin{array}{l}\text { Langmuir-Sips } \\
\text { model }\end{array}$ & Gas & $\begin{array}{l}\text { Polar and Nonpolar } \\
\text { Organic Compounds }\end{array}$ & Lee [57] \\
\hline $\begin{array}{l}\text { Carbon molecular } \\
\text { sieve }\end{array}$ & \begin{tabular}{|l|} 
Type-II \\
Type-IV \\
\end{tabular} & $\begin{array}{l}\text { Langmuir-Ising } \\
\text { model }\end{array}$ & Gas & $\mathrm{H}_{2} \mathrm{O}$ & Rutherford [59] \\
\hline $\begin{array}{l}\text { Carbon-based } \\
\text { honeycomb monoliths }\end{array}$ & Type-II & $\begin{array}{l}\text { Langmuir-Ising } \\
\text { model }\end{array}$ & Gas & $\mathrm{H}_{2} \mathrm{O}$ & Querejeta et al. [60] \\
\hline Polymer material & $\begin{array}{l}\text { Type-II } \\
\text { Type-V }\end{array}$ & $\begin{array}{l}\text { Modified Langmuir- } \\
\text { Ising model }\end{array}$ & Gas & Several alcohols & Malakhov et al. [61] \\
\hline Iron oxide & Not given & $\begin{array}{l}\text { QK Langmuir model } \\
\text { (QKLM) }\end{array}$ & Liquid & Natural organic matter & Gu et al. [43] \\
\hline $\begin{array}{l}\text { Metalorganic } \\
\text { Frameworks (MOFs) }\end{array}$ & \begin{tabular}{|l|} 
Type-V \\
Type-IV
\end{tabular} & $\begin{array}{l}\text { Rigorous theoretical } \\
\text { thermodynamic } \\
\text { models } \\
\end{array}$ & Gas & $\mathrm{CO}_{2}$, benzene & $\begin{array}{l}\text { Pera-Titus and } \\
\text { Farrusseng [30] }\end{array}$ \\
\hline Carbons & $\begin{array}{l}\text { Type-V } \\
\text { Type-II } \\
\end{array}$ & Several sigmoidal & Gas & $\mathrm{H}_{2} \mathrm{O}$ & $\begin{array}{l}\text { Furmaniak et al. } \\
{[11]}\end{array}$ \\
\hline $\begin{array}{l}\text { Chemically modified } \\
\text { agricultural solid } \\
\text { waste }\end{array}$ & $\begin{array}{l}\text { Type-II } \\
\text { Type-V }\end{array}$ & - & Liquid & Heavy metals & Mosa et al. [64] \\
\hline $\begin{array}{l}\text { Zeolitic imidazolate } \\
\text { frameworks (ZIFs) }\end{array}$ & $\begin{array}{l}\text { Type-II } \\
\text { Type-V }\end{array}$ & - & Gas & Ethanol/water & Zhang et al. [31] \\
\hline $\begin{array}{l}\text { Mesoporous } \\
\text { organosilicas }\end{array}$ & Type-V & - & Liquid & Heavy organic pollutants & Ganiyu et al. [65] \\
\hline $\begin{array}{l}\text { Metal-organic } \\
\text { frameworks (MOFs) }\end{array}$ & Type-IV & - & Gas & $\mathrm{CO}_{2}$ & Choi et al. [66] \\
\hline Synthetic zeolites & Type-II & - & Liquid & Pesticides & $\begin{array}{l}\text { Rasamimanana et } \\
\text { al. [67] }\end{array}$ \\
\hline \multicolumn{6}{|c|}{ Bio-sorption } \\
\hline Sargassun $s p$ & Type-II & Sips isotherm & Liquid & $\begin{array}{l}\text { Copper and chromium } \\
\text { ions }\end{array}$ & Steffen et al. [50] \\
\hline S. pombe & Type-II & Sips isotherm & Liquid & Nickel ions & Özen et al. [51] \\
\hline
\end{tabular}




\section{Conclusions}

An in-depth analysis of S-shaped isotherms and their dimensionless forms is presented, which is of great importance for modeling of separation and catalytic processes and interpretation of equilibrium data. In total thirteen S-shaped isotherms with a single inflection point are discussed and grouped into three groups, namely simple, hybrid and composite isotherms. The discussion includes theoretical, empirical and semi-empirical models for monolayer and multilayer adsorption and pore filling, excluding capillary condensation phenomena. As the review revealed, S-shaped isotherms are extensively encountered in all kinds of adsorption (gas and liquid) as well as in ion exchange systems. This study comes to complement the previously published literature on the equilibrium isotherms, covering insights on the physical basis and applications of S-shaped isotherms.

\section{References}

[1] K.Y. Foo, B.H. Hameed, Insights into the modeling of adsorption isotherm systems, Chem. Eng. J., 156 (2010) 2-10.

[2] V.J. Inglezakis, M.M. Fyrillas, Adsorption Fixed Beds Modeling Revisited; Generalized Solutions for S-Shaped Isotherms, Chem. Eng. Comm. 204 (2017) 1299-1317.

[3] C.H. Giles, D. Smith, A. Huitson, A general treatment and classification of the solute adsorption isotherm. I: Theoretical, J. Colloid Interf. Sci., 47 (1974) 755-765

[4] K.R. Hall, L.C. Eagleton, A. Acrivos, T. Vermeulen, Pore- and Solid-Diffusion Kinetics in Fixed-Bed Adsorption under Constant-Pattern Conditions, Ind. Eng. Chem. Fundam., 5 (1966) 212-223. 
[5] A.E.Rodrigues, Dynamics of Ion Exchange Processes, in: L.Liberti, F.G. Helfferich (Eds.) Mass Transfer and Kinetics of Ion Exchange, Kluwer Academic Publishers 1983, pp. 259-311.

[6] D.M. Ruthven, Principles of Adsorption and Adsorption Processes, Wiley, 1984.

[7] I. Park, K.S. Knaebel, Adsorption Breakthrough Behavior: Unusual Effects and Possible Causes, AIChE J., 38 (1992) 660-670.

[8] M. Hartmann, C. Bischof, Mechanical Stability of Mesoporous Molecular Sieve MCM-48 Studied by Adsorption of Benzene, n-Heptane, and Cyclohexane, J. Phys. Chem. B., 103 (1999) 6230-6235.

[9] G. Limousin, J.-P. Gaudet, L. Charlet, S. Szenknect, V. Barthes, M. Krimissa, Sorption isotherms: A review on physical bases, modeling and measurement, Appl. Geochem., 22 (2007) 249-275

[10] N. Ayawei, A.N. Ebelegi, D. Wankasi, Modelling and Interpretation of Adsorption Isotherms, J. Chem., Article ID 3039817 (2017) 11 pages.

[11] S. Furmaniak, P.A. Gauden, A.P. Terzyk, G. Rychlicki, Water adsorption on carbons Critical review of the most popular analytical approaches, Adv. Colloid Interface Sci., 137 (2008) 82-143.

[12] S. Brunauer, L.S. Deming, W.E. Deming, E. Teller, On a Theory of the van der Waals Adsorption of Gases, J. Am. Chem. Soc., 62 (1940) 1723-1732

[13] K.S.W. Sing, D.H. Everett, R.A.W. Haul, L. Moscou, R.A. Pierotti, J. Rouquerol, T. Siemieniewska, Reporting physisorption data for gas-solid systems with special reference to the determination of surface area and porosity, Pure Appl. Chem., 57 (1985) 603-619.

[14] C. Hinz, Description of sorption data with isotherm equations, Geoderma, 99 (2001) $225-243$. 
[15] M.T. Coltharp, On Numerical Classification of Solution Adsorption Isotherms, Langmuir, 21 (2005) 3475-3479.

[16] F.G. Helfferich, Ion Exchange, McGraw-Hill, New York, 1962.

[17] M.J. Slater, The Principles of Ion Exchange Technology, Butterworth-Heinemann, 1991.

[18] R.M. Barrer, J. Klinowski, Ion exchange involving several groups of homogeneous sites, J. Chem. Soc., Faraday Trans. 1, 68 (1972) 73-87.

[19] R.M. Barrer, J. Klinowski, Ion-exchange Selectivity and Electrolyte Concentration, J. Chem. Soc., Faraday Trans. 1, 70 (1974) 2080-2091.

[20] V.J. Inglezakis, Solubility-Normalized Dubinin-Astanhov adsorption isotherm for ion exchange systems, Microporous Mesoporous Mater., 103 (2007) 72-81.

[21] V. Inglezakis, The concept of "capacity" in zeolite ion exchange systems, J. Colloid Interf. Sci., 281 (2005) 68-79.

[22] A. Joly, A. Perrard, Linear driving force models for dynamic adsorption of volatile organic compound traces by porous adsorbent beds, Math. Comput. Simulat., 79 (2009) 3492-3499.

[23] A. Meghea, H.H. Rehner, I. Peleanu, R. Mihalache, Test-fitting on adsorption isotherms of organic pollutants from waste waters on activated carbon, J. Radioanal. Nucl. Chem., 229 (1998) 105-110.

[24] D. Burevski, The application of the Dubinin-Astakhov equation to the characterization of microporous carbons, Colloid Polym. Sci., 280 (1982) 623-627.

[25] A. Gil, P. Grange, Application of the Dubinin-Radushkevich and Dubinin-Astakhov equations in the characterization of microporous solids, Colloids Surf., A 113 (1996) $39-50$.

[26] T. Siemieniewska, K. Tomkbw, J. Kaczmarczyk, A. Albiniak, Application of the Dubinin-Astakhov Equation to Evaluation of Benzene and Cyclohexane Adsorption 
Isotherms on Steam Gasified Humic Acid Chars from Brown Coal, Energy Fuels, 4 (1990) 61-70.

[27] A.P. Terzyk, Molecular properties and intermolecular forces-factors balancing the effect of carbon surface chemistry in adsorption of organics from dilute aqueous solutions, J. Colloid Interf. Sci., 275 (2004) 9-29.

[28] P. Podkoscielny, K. Nieszporek, Heterogeneity of activated carbons in adsorption of phenols from aqueous solutions-Comparison of experimental isotherm data and simulation predictions, Appl. Surf. Sci., 253 (2007) 3563-3570.

[29] V.J. Inglezakis, M. Stylianou, M. Loizidou, Ion exchange and adsorption equilibrium studies on clinoptilolite, bentonite and vermiculite, J. Phys. Chem. Solid, 71 (2010) 279-284.

[30] M. Pera-Titus, D. Farrusseng, Guest-Induced Gate Opening and Breathing Phenomena in Soft Porous Crystals: Building Thermodynamically Consistent Isotherms, J. Phys. Chem. C, 116 (2012) 1638-1649.

[31] K. Zhang, R.P. Lively, C. Zhang, W.J. Koros, R.R. Chance, Investigating the Intrinsic Ethanol/Water Separation Capability of ZIF-8: An Adsorption and Diffusion Study, J. Phys. Chem. C, 117 (2013) 7214-7225.

[32] K.S.W. Sing, F. Rouquerol, J. Rouquerol, Classical Interpretation of Physisorption Isotherms at the Gas-Solid Interface, in: Adsorption by Powders and Porous Solids (Second Edition), 2014, pp. 159-189.

[33] S. Saevels, A.Z. Berna, J. Lammertyn, C. Di Natale, B.M. Nicolai, Characterization of QMB sensors by means of the BET adsorption isotherm, Sensors Actuators, B101 (2004) 242-251.

[34] W.F. Woodruff, A. Revil, CEC-normalized clay-water sorption isotherm, Water Resour. Res., 47 (2011). 
[35] Y. Tan, J.H. O'Haver, Use of the BET adsorption isotherm equation to examine styrene adsolubilization by nonionic surfactants at the water-silica interface, J. Colloid Interf. Sci., 279 (2004) 289-295.

[36] R.H. Stokes, R.A. Robinson, Ionic Hydration and Activity in Electrolyte Solutions, J. Am. Chem. Soc., 70 (1948) 1870.

[37] P. Letellier, A. Mayaffre, M. Turmine, Mixing behaviour of charged and non-charged surfactants described by BET isotherms, J. Colloid Interf. Sci., 337 (2009) 234-239.

[38] W.O. Rains, R.M. Counce, B.B. Spencer, Application of the Brunauer-Emmett-Teller isotherm to the water-nitric acid system for the determination of mean ionic activity coefficients, Chem. Eng. Commun., 171 (1999) 169-180.

[39] C.J. Radke, J.M. Prausnitz, Adsorption of Organic Solutes from Dilute Aqueous Solution on Activated Carbon, Ind. Eng. Chem. Fundam., 4 (1972) 445-451.

[40] T. Vermeulen, Separation by adsorption methods, Adv. Chem. Eng., 2 (1958) 147-208

[41] T. Vermeulen, M.D. LeVan, N.K. Hiester, G. Klein, Adsorption and Ion Exchange, in: R.H. Perry, D.W. Green (Eds.) Perry's Chemical Engineers' Handbook (6th ed.), McGraw-Hill, New York, 1984.

[42] M.A.S.D.d. Barros, N.R.C.F. Machado, F.V. Alves, E.F. SousaAguiar, Ion exchange mechanism of $\mathrm{Cr}+3$ on naturally occurring clinoptilolite, Braz. J. Chem. Eng., 14 (1997) 233-241.

[43] B. Gu, J. Schmitt, Z. Chen, L. Liang, J.F. McCarthy, Adsorption and desorption of natural organic matter on iron oxide: mechanisms and models, Environ. Sci. Technol., 28 (1994) 38-46.

[44] P.D. Grant, S.L. Lemke, M.R. Dwyer, T.D. Phillips, Modified Langmuir equation for SShaped and multisite isotherm plots, Langmuir, 14 (1998) 4292-4299. 
[45] B.Y. Zhu, T. Gu, Surfactant adsorption at solid-liquid interfaces, Adv. Colloid Interface Sci., 37 (1991) 1-32.

[46] G. Markou, D. Mitrogiannis, V. Inglezakis, K. Muylaert, N. Koukouzas, N. Tsoukalas, E. Kamitsos, P. D., I. Baziotis, $\mathrm{Ca}(\mathrm{OH}) 2$ pre-treated bentonite for phosphorus removal and recovery from synthetic and real wastewater, CLEAN - Soil, Air, Water, 46, $1700378(2018)$

[47] D.D. Do, Adsorption analysis: equilibria and kinetics, Imperial College Press, 1998.

[48] S. Kayal, S. Baichuan, B.B. Sah, Adsorption characteristics of AQSOA zeolites and water for adsorption chillers, Int. J. Heat Mass Transfer, 92 (2016) 1120-1127.

[49] A.A. Sharipova, S.B. Aidarova, N.Y. Bekturganova, A. Tleuova, R. Miller, Triclosan adsorption from model system by mineral sorbent diatomite, Colloids Surf. A, 532 (2017) 97-101.

[50] V. Steffen, E. Antonio da Silva, L. Roberto Evangelista, L. Cardozo-Filho, Phenomenological adsorption isotherm for a binary system based on PoissonBoltzmann equation, Surf. Interface, 10 (2018) 50-57.

[51] R. Özen, N.A. Sayar, S. Durmaz-Sam, A.A. Sayar, A sigmoidal model for biosorption of heavy metal cations from aqueous media, Math. Biosci., 265 (2015) 40-46.

[52] G.P. Jeppu, T.P. Clement, A modified Langmuir-Freundlich isotherm model for simulating pH-dependent adsorption effects, J. Contam. Hydrol., 129-130 (2012) 4653.

[53] O. Bricio, J. Coca, H. Sastre, Effect of the heterogeneity of macroporous Styrene-DVB resins on ion-exchange equilibria, Solvent Extr. Ion Exch., 15 (1997) 647-664.

[54] F. Pepe, D. Caputo, C. Colella, The Double Selectivity Model for the Description of IonExchange Equilibria in Zeolites, Ind. Eng. Chem. Res., 42 (2003) 1093-1097. 
[55] F. Iucolano, D. Caputo, F. Pepe, C. Colella, A thermodynamic model of chabazite selectivity for Pb2+, Stud. Surf. Sci. Catal., 155 (2005) 339-346.

[56] W.L. Hsu, S. Paul, J.A. Shamim, K. Kitaoka, H. Daiguji, Design and performance evaluation of a multilayer fixed-bed binder-free desiccant dehumidifier for hybrid airconditioning systems: Part II - Theoretical analysis, Int. J. Heat Mass Transfer, 116 (2018) 1370-1378.

[57] J.W. Lee, W.G. Shim, M.S. Yang, H. Moon, Adsorption Isotherms of Polar and Nonpolar Organic Compounds on MCM-48 at (303.15, 313.15, and 323.15) K, J. Chem. Eng. Data, 49 (2004) 502-509.

[58] X. Wu, M.N. Shahrak, B. Yuan, S. Deng, Synthesis and characterization of zeolitic imidazolate framework ZIF-7 for CO2 and CH4 separation, Microporous Mesoporous Mater., 190 (2014) 189-196.

[59] S.W. Rutherford, Modeling Water Adsorption in Carbon Micropores: Study of Water in Carbon Molecular Sieves, Langmuir, 22 (2006) 702-708.

[60] N. Querejeta, M.G. Plaza, F. Rubiera, C. Pevida, T. Avery, S.R. Tennisson, Carbon monoliths in adsorption-based post-combustion CO2 capture, Energy Procedia, 114 (2017) 2341-2352.

[61] A.O. Malakhov, V.V. Volkov, Cooperative multimolecular sorption equation: Application to an alcohol-poly(1-trimethylsilyl-1-propyne) system, Polym Sci, Ser A, $40(2000) 1120-1126$.

[62] M.A.S.D.d. Barros, N.R.C.F. Machado, F.V. Alves, E.F. Sousa-Aguiar, Ion exchange mechanism of $\mathrm{Cr} 3+$ on naturally occurring clinoptilolite, Braz. J. Chem. Eng., 14 (1997). 
[63] V.J. Inglezakis, K.J. Hadjiandreou, M.D. Loizidou, H.P. Grigoropoulou, Pretreatment of natural clinoptilolite in a laboratory-scale ion exchange packed bed, Water Res., 35 (2001) 2161-2166.

[64] A.A. Mosa, A. El-Ghamry, P. Trüby, Chemically Modified Crop Residues as a LowCost Technique for the Removal of Heavy Metal Ions from Wastewater, Water Air Soil Pollut, 217 (2011) 637-647.

[65] S.O. Ganiyu, G. Bispo, N. Bion, P. Ferreira, I. Batonneau-Gener, Periodic mesoporous organosilicas as adsorbents for the organic pollutants removal in aqueous phase, Microporous Mesoporous Mater., 200 (2014) 117-123.

[66] I.-H. Choi, H.S. Chae, S. Huh, S.J. Lee, S.-J. Kim, Y. Kim, Gas Sorption Properties of Isostructural Co-MOFs Containing Dipyridylporphyrin Linkers with Different Substituents at the 10,20-meso-Positions, Eur. J. Inorg. Chem., (2015) 2989-2995.

[67] S. Rasamimanana, S. Mignard, I. Batonneau-Gener, Hierarchical zeolites as adsorbents for mesosulfuron-methyl removal in aqueous phase, Microporous Mesoporous Mater., $226(2016) 153-161$. 